\title{
Evolving Editorial Processes at the Journal of Occupational Rehabilitation
}

\author{
Michael Feuerstein
}

Published online: 22 January 2015

(C) Springer Science+Business Media New York (outside the USA) 2015

Recent years have seen a rapid growth in the number and variety, of manuscript submissions to the Journal of Occupational Rehabilitation. The submissions received and processed by the Journal's editorial team and evaluated by its peer reviewers have nearly doubled in just the past 7 years, and the article submissions reflect a growing international perspective and diversity in disciplines, topics, and regional clinical and policy issues [1]. One consequence of this success is the increasing time and resources needed to manage the journal's peer review process and to carefully prioritize manuscripts for publication within a broadening range of expert areas. Another issue is the growing number of accumulated manuscripts awaiting print publication. These are good problems to have, as they reflect a maturing field of science [2], a growing number of trained practitioners and researchers [3], and an increasing number of publishable reports. Nevertheless, the higher volume of incoming manuscript submissions require changes to the current editorial process, and this was discussed at a gathering of certain Journal Editorial Board members at the Work Disability Prevention and Integration (WDPI) Conference, held in Toronto in October 2014. After this meeting and after consultation with a number of authors, reviewers, and Editorial Board members, I have identified several changes in the editorial review process that will be instituted over the next year:

\footnotetext{
M. Feuerstein $(\square)$

Departments of Medical and Clinical Psychology and Preventive Medicine and Biometrics, Uniformed Services University of the Health Sciences, 4301 Jones Bridge Road, Bethesda, MD 20814-4799, USA

e-mail: michael.feuerstein@usuhs.edu
}

- Drs. Patricia A. Findley and William S. Shaw, who have been managing many aspects of the "Editorial Manager" (i.e. electronic submission system) website electronic communication and peer review process, will be promoted to Senior Associate Editors, and their decision-making role will continue to expand in consultation with me as Editor-in-Chief.

- Some of the current Associate Editors will end their tenure in that position, and a group of new Associate Editors will be designated to serve as action editors, overseeing and managing the editorial review process within specific methodological and/or content area domains and making final recommendations for manuscript revisions and acceptance. Their recommendations will be forwarded to the Senior Associate Editors, who will be responsible for final decisions. I will continue to be responsible for the overall quality and direction of the manuscript review and publication process.

- For those manuscripts that are advanced to peer review, the Editorial team will strive to obtain at least two independent reviews for each manuscript before an editor decision is reached.

- In addition to writing specific critiques and comments, peer reviewers will be asked to complete four formal ratings of overall manuscript impact, as shown below.

In addition to any comments you have for the editor, please complete the following four global ratings, which will be helpful to the editor for assessing priority for publication:

1- Poor 2- Fair 3- Good 4- Very good 5- Excellent

1. Unique theoretical or scientific contribution in the area of occupational rehabilitation and work disability?

$$
\text { Poor }
$$
Fair Good Not applicable
Very good 
2. Practical or clinical significance in the area of occupational rehabilitation and work disability?

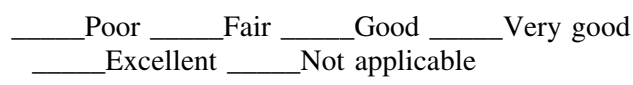

3. Conclusions are supported by study results and framed within study limitations?

Poor $\_$Excellent

4. Study rationale and results are integrated with existing literature and/or current practice?

_Poor ___ Fair ___ Good ___ Very good Excellent ___ Not applicable

By obtaining these specific ratings of overall impact, we intend to add a more transparent and systematic layer of peer scrutiny and additional checks and balances in terms of judging the theoretical and practical significance of submitted manuscripts.

- The current page capacity of the Journal (at 4 issues per year) will be maintained, but editorial decisions will become even more selective in an effort to prioritize submissions based on overall scientific and practical impact.

- Authors may be asked to limit page and word length of submitted manuscripts (or use on-line supplemental resources) to allow space for more articles in the printed version of the Journal.

- Membership on the Editorial Board will be limited to those who are active in the manuscript review process and/or whose expertise and training fall within areas that are vital to the Journal's continuing growth and direction.
- An annual survey of the Editorial Board will be scheduled for quality improvement and to solicit ideas for special supplements and other changes to Journal format and content.

- As always, any feedback or comments you wish to provide us regarding any aspect of the Journal are welcome. Comments may be forwarded to me (michael.feuerstein@usuhs.edu), to Dr. Findley (pfindley@ssw.rutgers.edu), or to Dr. Shaw (William.shaw@libertymutual.com).

I'd like to personally thank and congratulate the many authors, reviewers, and editorial board members who have dedicated time and energy to the Journal's success over the past 23 years. I expect the current changes to the editorial review process will help us prioritize important research in occupational rehabilitation and work disability research and practice and continue to maintain a multidisciplinary journal of high quality and impact.

\section{References}

1. Shaw WS, Findley PA, Feuerstein M. Twenty years of multidisciplinary research and practice. J Occup Rehabil. 2011;21(4): 449-54.

2. Pransky GS, Loisel P, Anema JR. Work disability prevention research: current and future prospects. J Occup Rehabil. 2011; 21(3):287-92.

3. Loisel P, Hong QN, Imbeau D, Lippel K, Guzman J, MacEachen E, Corbiére M, Santos BR, Anema JR. The Work Disability Prevention CIHR Strategic Training Program: program performance after 5 years of implementation. J Occup Rehabil. 2009; 19(1):1-7. 